\title{
In Focus
}

\section{Spotlight on the June 4 Issue}

\author{
Robert A. Gross, MD, PhD, FAAN \\ Editor-in-Chief, Neurology ${ }^{\circledR}$
}

\section{Brain metabolic changes suggestive of axonal damage in radiologically isolated syndrome}

Twenty-three patients with radiologically isolated syndrome (RIS) underwent proton magnetic resonance spectroscopic imaging ( $\left.{ }^{1} \mathrm{H}-\mathrm{MRSI}\right)$ to measure levels of $\mathrm{N}$-acetylaspartate (NAA) and choline normalized to creatine $(\mathrm{Cr})$ compared to 20 controls. Decreased brain NAA/Cr ratios indicate that brain metabolic abnormalities suggestive of axonal damage may be useful for stratifying RIS individuals with a high risk of progression to multiple sclerosis.

See p. 2090; Editorial, p. 2084

\section{Pilot trial of clenbuterol in spinal and bulbar muscular atrophy}

This trial suggests that clenbuterol may be effective and safe in treating spinal bulbar muscular atrophy (SBMA). A 6-minute walk distance, a biomarker of motor impairment in SBMA, increased during a $12-$ month treatment with oral clenbuterol $(0.04 \mathrm{mg} /$ day $)$ in 20 patients with SBMA.

See p. 2095

\section{Vestibular impairment in patients with Charcot-Marie-Tooth disease}

This study assessed the high-acceleration vestibulo-ocular reflex of the semicircular canals in 15 patients with Charcot-Marie-Tooth (CMT) who underwent cervical vestibular-evoked myogenic potentials, compared to controls. Cervical vestibular-evoked myogenic potentials may be more sensitive than quantitative head-impulse testing for detecting vestibular involvement in CMT, especially at an early disease stage.

See p. 2099

Mild cognitive impairment: Incidence and vascular risk factors in a population-based cohort

Whether defined neuropsychologically or functionally by Clinical Dementia Rating (CDR), mild cognitive impairment (MCI) incidence increases with age and does not vary by sex or education. Several vascular risk factors elevate the risk of developing $\mathrm{MCl}$; most were associated with nonamnestic $\mathrm{MCl}$ and $\mathrm{CDR}=0.5$. Controlling vascular risk may reduce risk of $\mathrm{MCl}$.

See p. 2112
Comparison of symptomatic and asymptomatic persons with Alzheimer disease neuropathology

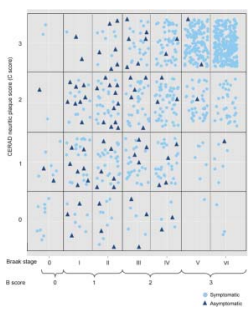

The authors identified 82 asymptomatic and 824 symptomatic persons with low to high Alzheimer disease neuropathologic changes at autopsy. While the severity of the pathology, particularly neurofibrillary tangles, played a large role in determining the extent of symptoms, other factors, including age, APOE status and comorbidities also explained differences in clinical presentation.

See p. 2121

\section{Application of the National Institute on Aging-Alzheimer's Association AD criteria to ADNI}

This study included patients with Alzheimer disease (AD) dementia with at least one amyloid biomarker. When using a requirement that patients have a positive amyloid biomarker and a single neuronal injury marker having an AD pattern, $87 \%$ (48\% for both neuronal injury biomarkers) could be categorized as "high probability" for AD. See p. 2130

Migraine, depression, and brain volume: The AGES-Reykjavik Study Participants from the AGES-Reykjavik Study were assessed for migraine headache according to modified International Classification of Headache Disorders-II criteria. Lifetime history of major depressive disorder was diagnosed according to DSM-IV criteria. Reporting both migraine and major depressive disorder was associated with smaller brain tissue volumes than having one or neither of these conditions. See p. 2138

Severe carotid stenosis and impaired cerebral hemodynamics can influence cognitive deterioration

Two hundred and ten subjects with asymptomatic severe carotid stenosis and 109 controls were evaluated for a 36-month period. The presence of stenosis influenced cognitive deterioration, especially when associated with a hemodynamic impairment. Evaluation of functional consequences of carotid stenosis is important to better define patients' risk profile. See p. 2145

From editorialists Lazar \& Marshall: “... cognition may be a more sensitive index of brain integrity than those physical functions more typically measured in studies of cerebrovascular disease."

See p. 2086

NB: "The lost resident: Why resident physicians still need mentoring," see p. e244. To check out other Resident \& Fellow Opinion $\&$ Special Articles, point your browser to www.neurology.org and click on the link to the Resident \& Fellow Section. 


\section{Neurology}

\section{Spotlight on the June 4 Issue}

Robert A. Gross

Neurology 2013;80;2083

DOI 10.1212/WNL.0b013e3182972e91

\section{This information is current as of June 3, 2013}

\section{Updated Information \&} Services

Permissions \& Licensing

Reprints including high resolution figures, can be found at: http://n.neurology.org/content/80/23/2083.full

Information about reproducing this article in parts (figures,tables) or in its entirety can be found online at:

http://www.neurology.org/about/about_the_journal\#permissions

Information about ordering reprints can be found online:

http://n.neurology.org/subscribers/advertise

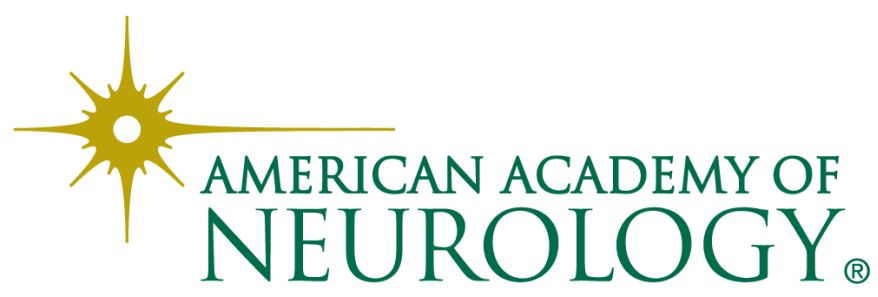

